\title{
Dye adsorption behavior of Luffa cylindrica fibers
}

\author{
H. Demir*, A. Top, D. Balköse, S. Ülkü \\ Izmir Institute of Technology, Faculty of Engineering, Department of Chemical Engineering, \\ Gülbahce Campus, 35430 Urla Izmir, Turkey
}

Received 10 April 2007; received in revised form 18 July 2007; accepted 27 August 2007

Available online 31 August 2007

\begin{abstract}
Using natural Luffa cylindrica fibers as adsorbent removal of methylene blue dye from aqueous solutions at different temperatures and dye concentrations was investigated in this study. Thermodynamics and kinetics of adsorption were also investigated. The adsorption isotherms could be well defined with Langmuir model instead of Freundlich model. The thermodynamic parameters of methylene blue (MB) adsorption indicated that the adsorption is exothermic and spontaneous. The average MB adsorption capacity was found out as $49 \mathrm{mg} / \mathrm{g}$ and average BET surface area of fibers was calculated as $123 \mathrm{~m}^{2} / \mathrm{g}$.
\end{abstract}

(C) 2007 Elsevier B.V. All rights reserved.

Keywords: Adsorption; Dye; Color removal; Luffa cylindrica; Thermodynamics

\section{Introduction}

Many industries, mostly textile industry, propagate colored effluents containing dyes and pigments. The colored effluents generally discharge to natural water sources at low concentration, which may be accepted at inert and non-toxic level. Many dyes and pigments are toxic and have carcinogenic and mutagenic effects that influenced environment and also human. The colored effluents become a major environmental problem because of the difficulty in removing by conventional physicochemical and biological treatment process. Liquid-phase adsorption has been shown to be an effective way of removing suspends solids, odors, organic matter and oil from aqueous solutions [1-4].

Different adsorbents have been used for removing colored effluents from aqueous solutions. Activated carbon is the most widely used adsorbent for this purpose as a result of its high adsorption capacity, with a handicap of being very expensive product. This has led scientists to research for cheaper adsorbents. One of the most researched substitutes is cellulose-based materials. The cellulose-based materials are quite cheap, renewable and biodegradable $[5,6]$.

\footnotetext{
* Corresponding author. Tel.: +90 232750 6680; fax: +90 2327506645 . E-mail address: hasandemir@iyte.edu.tr (H. Demir).
}

Luffa sponge products are readily available in the cosmetic and bath section of department stores, discount stores, pharmacies and specialty shops. Luffa cylindrica belongs to the curcubitacea family and is commonly grown in China, Japan and other countries in Asia and Central and South America. Luffa sponge mainly composed of cellulose, hemicellulose and lignin, thus $L$. cylindrica is called as lignocellulosic material. $L$. cylindrica has a fibrous vascular system that can allow removal of water pollutants. Moreover, many environmentally conscious consumers appreciate that luffa products are biodegradable, natural and renewable resources. The tough fibers can promise as being processed into industrial products such as filters, insulation and packing materials [7-12].

Methylene blue (MB) is a basic blue dyestuff with chemical formula of $\mathrm{C}_{16} \mathrm{H}_{18} \mathrm{~N}_{3} \mathrm{SCl}$. Methylene blue has several harmful effects in spite of being not strongly hazardous. It is harmful when it is swallowed and it can be harmful if it is breathed and in contact with skin. Moreover, it causes severe eye irritation [13]. In previous studies, the MB adsorption capacities of various low cost adsorbents, such as rice husk, wheat shells, banana and orange peels, etc. were investigated and are shown in Table 1.

In this study, luffa fiber was investigated as an alternative adsorbent to the expensive ones for removing dye, i.e. methylene blue, from aqueous solutions. The adsorbed amounts of dye were measured in equilibrium. Kinetic parameters were investigated to determine the ratio of reaction time versus adsorbed amounts. The optimum process temperature was also investigated. 
Table 1

Methylene blue adsorption capacities of various adsorbents

\begin{tabular}{lll}
\hline Adsorbent & $Q_{\mathrm{m}}(\mathrm{mg} / \mathrm{g})$ & Ref. \\
\hline Indian rosewood sawdust & $11.8-51.4$ & \\
Rice husk & 40.58 & \\
Neem leaf & $8.76-19.61$ & \\
Pyrophyllite & 70.42 & {$[14]$} \\
Jute processing waste & 22.47 & \\
Eggshell and eggshell membrane & $0.80-0.24$ & \\
Wheat shells & $16.56-21.50$ & \\
Banana peel & 15.9 & {$[5]$} \\
Orange peel & 13.9 & \\
Fly ash & 13.42 & {$[14]$} \\
Activated carbon & 435 & {$[3]$} \\
Kaolin & 13.99 & \\
\hline
\end{tabular}

\section{Materials and methods}

\subsection{Materials}

L. cylindrica fibers were obtained from a local specialty shop. The luffa fibers were washed with water to remove the adhering dirt. They were dried in an oven at $70{ }^{\circ} \mathrm{C}$ for $6 \mathrm{~h}$. After drying, they were cut with Waring Blendor for reducing dimensions to $2-3 \mathrm{~mm}$. Fibers were pretreated with $0.1 \mathrm{M}$ sodium hydroxide $(\mathrm{NaOH})$ solution at boiling temperature for $20 \mathrm{~min}$ in order to increase hydrophilicity of fiber. Fibers were washed with distilled water until all sodium hydroxide was removed. After washing, they were dried in oven at $70^{\circ} \mathrm{C}$ for $6 \mathrm{~h}$.

Sodium hydroxide (Sigma, 99\%), methylene blue $(99.9 \%$ from Aldrich) were used in the experiments.

\subsection{Methods}

The surface and cross section of luffa fibers were observed with a Philips XL-305 FEG - Scanning Electron Microscope after coating them with gold.

In adsorption experiments: $80 \mathrm{mg}$ of dried luffa fibers were immersed in $100 \mathrm{~cm}^{3} \mathrm{MB}$ solution having concentrations between 10 and $100 \mathrm{mg} / \mathrm{dm}^{3}(10,20,30,40,50,60,70,80$, $\left.90,100 \mathrm{mg} / \mathrm{dm}^{3}\right)$. The samples were put into Gerhardt Thermoshake machine at $20,30,40$ and $50{ }^{\circ} \mathrm{C}$ with $100 \mathrm{rpm}$. After

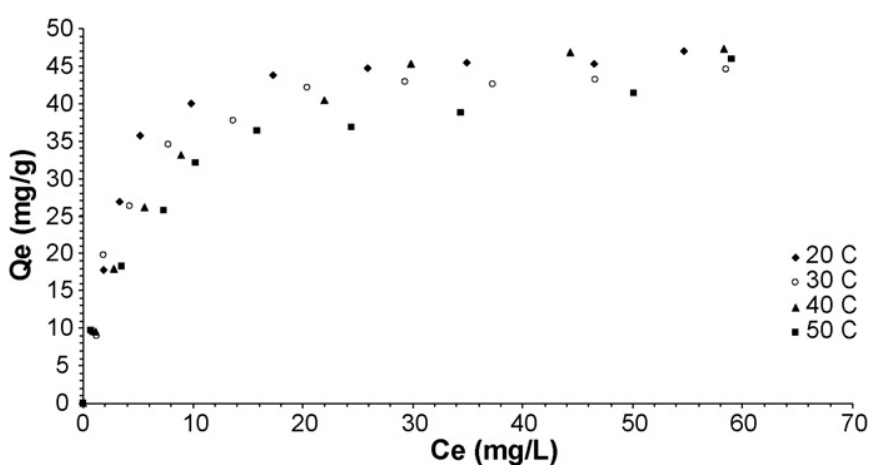

Fig. 2. Change of methylene blue adsorption with time at different medium temperatures.

shaking for $120 \mathrm{~h}$, the equilibrium concentrations of the solution samples were measured using a Shimadzu UV-1601 visible spectrophotometer.

The kinetics of the adsorption were researched by performing batch experiments at constant temperatures (303 and $323 \mathrm{~K}$ ) with a fixed MB concentration $\left(6 \mathrm{mg} / \mathrm{dm}^{3}\right)$ and fixed amount of luffa fiber (200 mg).

\section{Results and discussion}

Morphologies of the natural and modified fibers are as shown in Fig. 1. Sodium hydroxide treated luffa fiber is shown in Fig. 1b. Small holes having $1 \mu \mathrm{m}$ diameter were observed on the surface of fibers. As shown in Fig. 1b, luffa fibers include small empty channels having $1-10 \mu \mathrm{m}$ diameter in its structure.

\subsection{Adsorption isotherms}

Fig. 2 illustrates adsorption isotherms of MB onto luffa fibers at various medium temperatures. Methylene blue adsorption isotherms changed with respect to medium temperature. Changes were significant at decline of isotherms. Increment in medium temperature decreased the slopes of isotherms. At high temperatures, adsorption reduced. At equilibrium plateau, amount of adsorbed MB values were very close to each other. The amounts of adsorbed MB at equilibrium were approximately 46, 44, 47 and $42 \mathrm{mg}$ for medium temperatures of 20,30, 40
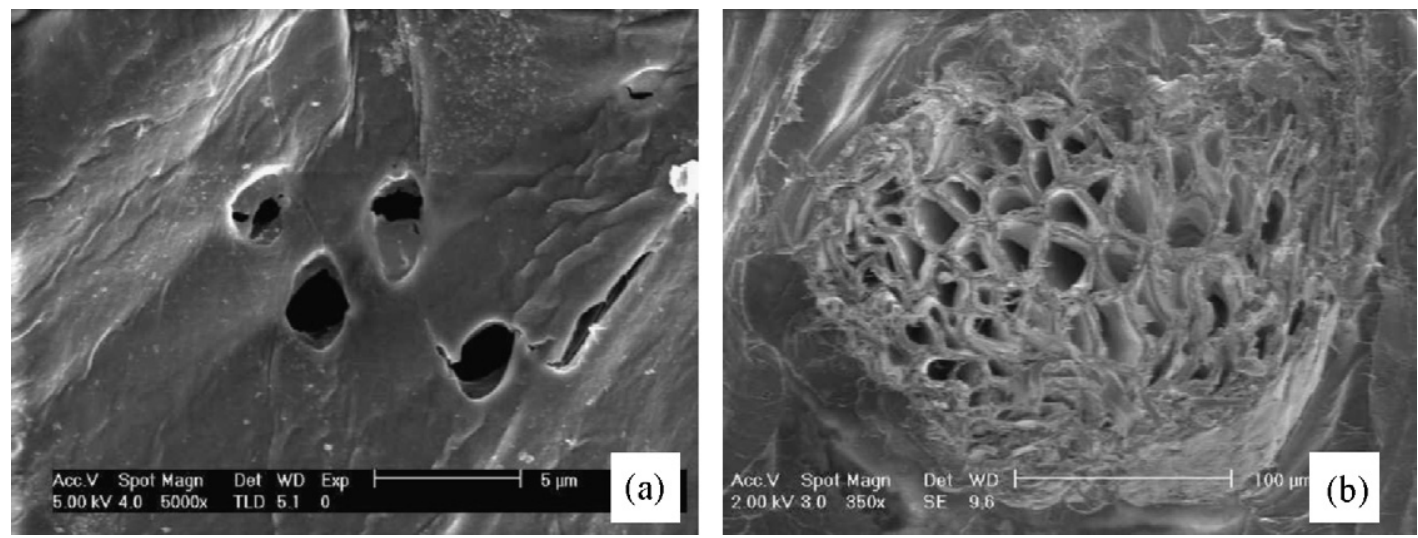

Fig. 1. SEM images of (a) NaOH treated surface (b) cross section of luffa fibers. 
and $50{ }^{\circ} \mathrm{C}$, respectively. At equilibrium, $\mathrm{MB}$ adsorption onto luffa could be influenced by luffa fiber surface energy system and concentration MB in aqueous solution. Therefore, effects of medium temperature on adsorption could not be significant for equilibrium.

The amount of MB adsorbed onto luffa fibers, $q_{\mathrm{e}}(\mathrm{mg} / \mathrm{g})$, was calculated by a mass balance according to Eq. (1) $[5,6]$.

$q_{\mathrm{e}}=\left(C_{\mathrm{o}}-C_{\mathrm{e}}\right) \frac{V}{M}$

where

$C_{\mathrm{o}}$ : initial liquid phase concentration of $\mathrm{MB}(\mathrm{mg} / \mathrm{l})$,

$C_{\mathrm{e}}$ : equilibrium liquid phase concentration of $\mathrm{MB}(\mathrm{mg} / \mathrm{l})$,

$V$ : volume of the solution (1),

$M$ : mass of the luffa fibers $(\mathrm{g})$.

The adsorption isotherms were evaluated by using Langmuir and Freundlich equations [5,6].

Langmuir isotherm equation is

$\frac{1}{q_{\mathrm{e}}}=\frac{1}{q_{\mathrm{m}}}+\frac{1}{K_{\mathrm{L}} q_{\mathrm{m}}} \frac{1}{C_{\mathrm{e}}}$

where

$K_{\mathrm{L}}=$ Langmuir constant $(1 / \mathrm{mg})$,

$q_{\mathrm{e}}=\mathrm{MB}$ concentration at equilibrium in fiber $(\mathrm{mg} / \mathrm{g})$,

$C_{\mathrm{e}}=\mathrm{MB}$ concentration at equilibrium in solution $(\mathrm{mg} / \mathrm{l})$,

$q_{\mathrm{m}}=\mathrm{MB}$ concentration when monolayer forms onto fiber (mg/g).

The Freundlich isotherm equation is

$q_{\mathrm{e}}=K_{\mathrm{f}} C_{\mathrm{e}}^{n}$

where

$K_{\mathrm{f}}=$ sorption capacity,

$n=$ sorption intensity.

The Freundlich constants of the isotherms $K_{\mathrm{f}}$ and $n$ were found by drawing $\log q_{\mathrm{e}}$ versus $\log C_{\mathrm{e}}$ and Langmuir constants of the isotherms $q_{\mathrm{m}}$ and $K_{\mathrm{L}}$ were evaluated by plotting $1 / q_{\mathrm{e}}$ versus $1 / C_{\mathrm{e}}$. Table 2 shows that the adsorption model constants of MB on luffa fibers can be described better by the Langmuir equation since a higher linear regression correlation coefficient, $R^{2}$, of 0.99 was obtained for this model. The Freundlich equation is often used for heterogeneous surface energy systems. Hence, it can be said that surface of luffa fiber has homogeneous energy surface. The adsorption capacities $\left(q_{\mathrm{m}}\right)$ of fibers depend on their surface areas. The BET (Brunauer, Emmett, Teller) surface areas of luffa fibers were found as 124, 114, 132 and $121 \mathrm{~m}^{2} / \mathrm{g}$, according to Eq. (4), for the temperatures of $20,30,40$ and $50{ }^{\circ} \mathrm{C}$, respectively. Annadurai et al. [5] reported BET surface areas of banana and orange peels as 21 and $24 \mathrm{~m}^{2} / \mathrm{g}$. The MB sorption capacities of L. cylindrica fibers (between 47 and $52 \mathrm{mg} / \mathrm{g}$ ) are higher than that of other cellulose wastes that shown in Table 1 . Such as orange peel and banana peel having 13 and $15 \mathrm{mg} / \mathrm{g} \mathrm{MB}$ adsorption capacities, respectively [5]. Based on these properties we can say that $L$. cylindrica fibers can be used efficiently for removing dye from aqueous solution instead of other cellulosic-based adsorbents. Moreover, the dye adsorption capacity of luffa fibers is closer to dye adsorption capacity of activated carbon than inorganic (fly ash, Pyrophyllite and Kaolin) and cellulosic-based adsorbents $[13,15]$.

BET surface area $=q_{\mathrm{m}} N_{\mathrm{o}} s 10^{-20}$

where

$N_{\mathrm{o}}$ : Avogadro number $\left(6.0221415 \times 10^{23}\right)$, $s$ : MB surface area (16 ̊ length and $8.4 \AA$ width) [13], $q_{\mathrm{m}}$ : monolayer adsorption from Langmuir model.

A further analysis for revealing favorable adsorption of luffa the Langmuir isotherm can be expressed in terms of a dimensionless equilibrium parameter $\left(R_{\mathrm{L}}\right)$ as shown in Eq. $(5)[3,6]$.

$R_{\mathrm{L}}=\frac{1}{1+K_{\mathrm{L}} C_{\mathrm{e}}}$

where

$K_{\mathrm{L}}=$ Langmuir constant,

$C_{\mathrm{e}}=\mathrm{MB}$ concentration at equilibrium in solution, $\mathrm{mg} / \mathrm{l}$.

The value of $R_{\mathrm{L}}$ represents the type of the isotherm to be either unfavorable $\left(R_{\mathrm{L}}>1\right)$, linear $\left(R_{\mathrm{L}}=1\right)$, favorable $\left(0<R_{\mathrm{L}}<1\right)$ or irreversible $\left(R_{\mathrm{L}}=0\right)$. Values of $R_{\mathrm{L}}$ are evaluated as $0.059,0.077$, 0.111 and 0.111 for $20,30,40$ and $50{ }^{\circ} \mathrm{C}$, respectively. The results confirmed that the maximum $\mathrm{MB}$ adsorption on luffa can be obtained under the medium condition of $20^{\circ} \mathrm{C}$. Generally, luffa fiber can be accepted as appropriate for the MB adsorption at any medium temperature since $R_{\mathrm{L}}$ values were found quite close to zero. This situation can also be interpreted as the

Table 2

Langmuir and Freundlich constants for methylene blue adsorption

\begin{tabular}{|c|c|c|c|c|c|c|}
\hline \multirow[t]{2}{*}{ Temperature $\left({ }^{\circ} \mathrm{C}\right)$} & \multicolumn{3}{|c|}{ Langmuir isotherm } & \multicolumn{3}{|c|}{ Freundlich isotherm } \\
\hline & $q_{\mathrm{m}}(\mathrm{mg} / \mathrm{g})$ & $K_{\mathrm{L}}(1 / \mathrm{mg})$ & $R^{2}$ & $K_{\mathrm{f}}(\mathrm{mg} / \mathrm{g})$ & $n$ & $R^{2}$ \\
\hline 20 & 49 & 0.4 & 0.9990 & 16 & 3 & 0.8343 \\
\hline 40 & 52 & 0.2 & 0.9993 & 12 & 3 & 0.9108 \\
\hline 50 & 47 & 0.2 & 0.9913 & 12 & 3 & 0.9545 \\
\hline
\end{tabular}


Table 3

Thermodynamic parameters for methylene blue adsorption on Luffa cylindrica at equilibrium

\begin{tabular}{lllllll}
\hline$q_{\mathrm{e}}(\mathrm{mmol} / \mathrm{g})$ & $\begin{array}{l}-\Delta H^{\circ} \\
(\mathrm{kJ} / \mathrm{mol})\end{array}$ & $\begin{array}{l}\Delta S^{\circ} \\
(\mathrm{J} / \mathrm{mol} \mathrm{K})\end{array}$ & \multicolumn{4}{c}{$-\Delta G^{\circ}(\mathrm{kJ} / \mathrm{mol})$} \\
\cline { 5 - 7 } & & & $293 \mathrm{~K}$ & $303 \mathrm{~K}$ & $313 \mathrm{~K}$ & $323 \mathrm{~K}$ \\
\hline 0.05 & 20.0 & 61.6 & 38.0 & 38.6 & 39.3 & 39.9 \\
0.07 & 20.0 & 61.5 & 38.0 & 38.6 & 39.3 & 39.9 \\
0.08 & 20.0 & 61.5 & 38.0 & 38.6 & 39.3 & 39.9 \\
0.10 & 20.0 & 61.5 & 38.0 & 38.6 & 39.3 & 39.9 \\
0.12 & 20.0 & 61.5 & 38.0 & 38.6 & 39.3 & 39.9 \\
Average & 20.0 & 61.5 & 38.0 & 38.6 & 39.3 & 39.9 \\
\hline
\end{tabular}

adsorption of $\mathrm{MB}$ on luffa is a relatively irreversible reaction $[3,6,16-18]$.

\subsection{Thermodynamic parameters}

Thermodynamic parameters for MB adsorption onto luffa fiber are the free energy of adsorption $\left(\Delta G^{\circ}\right)$, change of enthalpy of adsorption $\left(\Delta H^{\circ}\right)$ and change of entropy of adsorption $\left(\Delta S^{\circ}\right)$. These parameters are calculated for four different temperatures by using following equations $[3,6,16-17]$ :

$\Delta G^{\circ}=\Delta H^{\circ}-T \Delta S^{\circ}$

$\ln \left(\frac{q_{\mathrm{e}}}{C_{\mathrm{e}}}\right)=\frac{\Delta S^{\circ}}{R}-\frac{\Delta H^{\circ}}{R T}$

where

$q_{\mathrm{e}}=\mathrm{MB}$ concentration at equilibrium in fiber $(\mathrm{mmol} / \mathrm{g})$,

$R=$ Universal gas constant, $8.314(\mathrm{~J} / \mathrm{mol} / \mathrm{K})$,

$C_{\mathrm{e}}=\mathrm{MB}$ concentration at equilibrium in solution $(\mathrm{mmol} / \mathrm{g})$.

The values of $\Delta H^{\circ}$ and $\Delta S^{\circ}$ were determined from the slope and the intercept on the plot of $\ln \left(q_{\mathrm{e}} / C_{\mathrm{e}}\right)$ versus $1 / T$. Table 3 reveals the evaluated thermodynamic values of $\mathrm{MB}$ adsorption onto luffa fibers at constant amount of adsorbed MB. The negative values of $\Delta H^{\circ}$ indicate that $\mathrm{MB}$ adsorption onto luffa fiber is an exothermic reaction. The absolute magnitude of average $\Delta H^{\circ}$ is approximately $20 \mathrm{~kJ} / \mathrm{mol}$. An adsorption process is generally considered as physical if $\Delta H^{\circ}<25 \mathrm{~kJ} / \mathrm{mol}$ and as chemical when $\Delta H^{\circ}>40 \mathrm{~kJ} / \mathrm{mol}$. The absolute magnitude of $\Delta H^{\circ}$ did not change according to the amount of adsorbed MB. This phenomenon indicates that luffa fiber surface has homogeneous surface. The negative values of free energy indicate spontaneous adsorption without requiring large activation energy [14,16-18]. The values of free energy decreased with increasing amount of adsorbed MB since active sites of luffa fiber were occupied by MB molecules.

\subsection{Adsorption kinetics}

Fig. 3 illustrates plot of the amount of MB adsorption versus contact time for different temperatures (303 and $323 \mathrm{~K}$ ). The amount of MB adsorption during the first 1500 min was more rapid at $323 \mathrm{~K}$ than that of at $303 \mathrm{~K}$. After this period, the

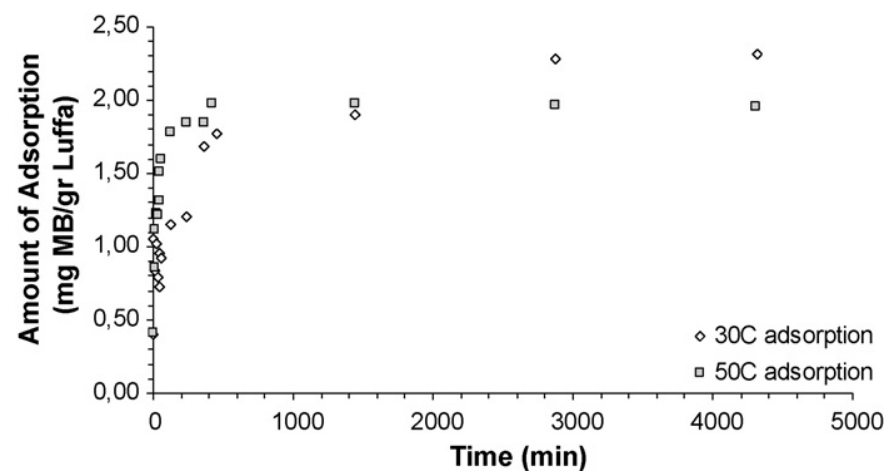

Fig. 3. Methylene blue adsorption isotherms with respect to time at different medium temperatures.

amount of dye adsorption increased at the lower temperatures and finally reached the equilibrium. The Langergren equation was performed on kinetics of $\mathrm{MB}$ adsorption process in order to research applicability of the pseudo-first order equation as follows $[5,6,14]$.

$\log \left(q_{\mathrm{e}}-q_{t}\right)=\log q_{\mathrm{e}}-\left(\frac{k_{1}}{2.303}\right) t$

where

$q_{t}=$ the amount of adsorbed MB at any time $(\mathrm{mg} / \mathrm{g})$,

$k_{1}=$ the equilibrium rate constant of pseudo-first order adsorption $\left(\min ^{-1}\right)$.

The slope of the plot of $\log \left(q_{\mathrm{e}}-q_{t}\right)$ versus $t$ gives the equilibrium rate constant of pseudo-first order adsorption. The value of linear regression correlation coefficient $\left(R^{2}\right)$ indicates whether adsorption is pseudo-first order or not. The rate constant of pseudo-first order adsorption and linear regression correlation coefficient are revealed in Table 4. The results indicated that the MB adsorption on luffa fiber was not a first

Table 4

Kinetic parameters of methylene blue adsorption on luffa fiber

\begin{tabular}{lll}
\hline Parameters & Temperature $(\mathrm{K})$ & \\
\cline { 2 - 3 } & 303 & 323 \\
\hline$q_{\mathrm{e}}(\mathrm{mg} / \mathrm{g})_{\text {Experimental }}$ & 2.3 & 1.96 \\
Pseudo-first order & & \\
$\quad k_{1}\left(\mathrm{~min}^{-1}\right)$ & $1.38 \times 10^{-3}$ & 0.011 \\
$q_{\mathrm{e}}(\mathrm{mg} / \mathrm{g})$ Calculated & 1.46 & 1.02 \\
$R^{2}$ & 0.83 & 0.94 \\
Pseudo-second order & & \\
$k_{2}\left(\mathrm{~g} \mathrm{mg}^{-1} \mathrm{~min}^{-1}\right)$ & $4.8 \times 10^{-3}$ & 0.042 \\
$q_{\mathrm{e}}\left(\mathrm{mg}_{\mathrm{g}}\right)$ Calculated & 2.32 & 1.97 \\
$R^{2}$ & 0.99 & 1 \\
Intraparticle diffusion & & \\
$k_{\mathrm{p}}\left(\mathrm{mg} \mathrm{g}^{-1}\right.$ min $\left.^{-1 / 2}\right)$ & 0.088 & 0.226 \\
$R^{2}$ & 0.80 & 0.76 \\
Diffusion coefficient & & $6.60 \times 10^{-14}$ \\
$D\left(\mathrm{~m}^{2} / \mathrm{s}\right)$ & $4.13 \times 10^{-13}$ & 0.59 \\
$R^{2}$ & 0.72 & \\
\hline
\end{tabular}




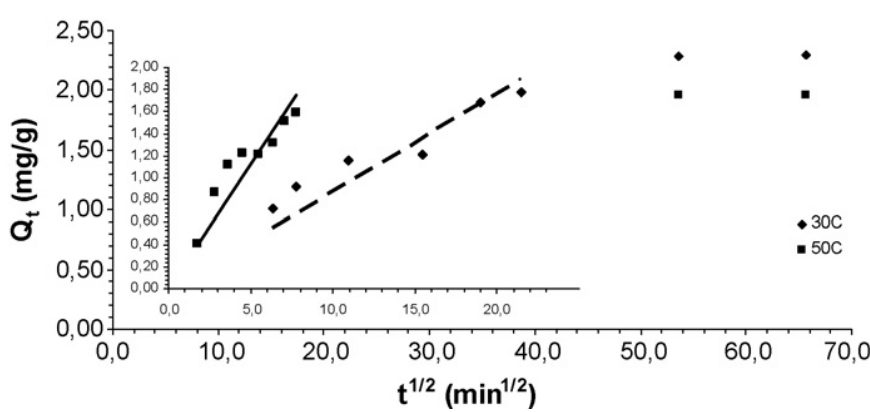

Fig. 4. The intraparticle diffusion model for methylene blue adsorption on luffa fiber at different temperatures.

order reaction according to its low linear regression coefficient.

The Ho's equation (Eq. (9)) was analyzed for applicability of pseudo-second order kinetics on adsorption of MB. The plot of $t / q_{\mathrm{e}}$ versus $t$ illustrates linear relation for second order kinetics [14].

$\frac{t}{q_{t}}=\frac{1}{k_{2} q_{\mathrm{e}}^{2}}+\frac{t}{q_{\mathrm{e}}}$

where $k_{2}=$ The rate constant of pseudo-second order adsorption (g/mg min).

The calculated $k_{2}, q_{\mathrm{e}}$ and linear regression coefficient values are shown in Table 4. The linear regression coefficients were greater than 0.99 that indicated the validity of pseudo-second order kinetics for both temperatures. However, calculated amount of adsorbed MB at equilibrium values were very close to experimental values.

The transportation of adsorbate molecules from the bulk of the solution to the solid surface with intraparticle diffusion process is often rate limiting step in many adsorption processes. Therefore, rate parameters for intraparticle diffusion $\left(k_{\mathrm{p}}\right)$ were determined by following model $[14,16-18]$.

$q_{t}=k_{\mathrm{p}} t^{1 / 2}$

where $k_{\mathrm{p}}=$ intraparticle diffusion rate constant $\left(\mathrm{mol} / \mathrm{g} \min ^{1 / 2}\right)$.

Fig. 4 illustrates intraparticle diffusion model for MB adsorption. Both of the plots for two temperatures were composed of linear portion and plateau. The linear portion was attributed to the intraparticle diffusion and the second portion of curve, plateau indicated equilibrium state. The values of intraparticle diffusion rate constant from the slope of straight lines are listed in Table 4.

Kinetic parameters of MB adsorption on luffa fiber indicated that the MB adsorption is a pseudo-second order reaction according to the comparison between linear regression coefficients of first and second order models. The intraparticle diffusion did not control the adsorption process since the linear regression coefficient of model was not close to 0.99 . Moreover, when medium temperature was $323 \mathrm{~K}$, intraparticle diffusion model was not satisfactory for MB adsorption on luffa fiber with a poor linear regression coefficient.

The kinetic data were employed to find MB diffusion coefficient on luffa fiber. The equation was simplified by Crank and used for short periods [19]. The model assumed that concentration of MB in solution is always uniform that satisfied with stirring solution. The luffa fiber was assumed to be infinitely long cylinder, since cross sectional diameter $(\sim 0.2 \mathrm{~mm}$ as shown in Fig. 1e) of luffa fiber is very smaller than lateral dimension of fiber $(2 \mathrm{~mm})$.

$\frac{M_{t}}{M_{\infty}}=\frac{4}{a} \sqrt{\frac{D t}{\pi}}$

where

$M_{t}=$ the mass of MB absorbed in a time $t(\mathrm{mg} / \mathrm{g})$,

$M_{\infty}=$ the mass of $\mathrm{MB}$ at equilibrium $(\mathrm{mg} / \mathrm{g})$,

$a=$ radius of the luffa fiber (m),

$D=$ diffusion coefficient $\left(\mathrm{m}^{2} / \mathrm{s}\right)$.

$k_{\mathrm{p}}$ in Eq. (10) equals to $q \infty(4 / a)(D / \Pi)^{1 / 2}$ as will be found from Eq. (11). The diffusion coefficients were found as $6.60 \times 10^{-14}$ and $4.13 \times 10^{-13} \mathrm{~m}^{2} / \mathrm{s}$ at 50 and $30^{\circ} \mathrm{C}$, respectively by using early time experimental data and Eq. (11) and were also reported in Table 4 . The diffusion coefficient at $50^{\circ} \mathrm{C}$ was higher than that of $30^{\circ} \mathrm{C}$ since initial $\mathrm{MB}$ adsorption at $50^{\circ} \mathrm{C}$ occurs more rapidly as shown in Fig. 3. The linear regression coefficients of model were less than 0.99 for both 30 and $50{ }^{\circ} \mathrm{C}$ medium temperatures. The diffusion model was not appropriate for MB diffusion into luffa fiber since surface holes on luffa fiber and longitudinal empty channels in the fibers accelerated diffusion of MB.

\section{Conclusion}

At equilibrium, the amount of adsorbed MB by L. cylindrica fiber was not influenced by medium temperature since the amount of active sites of luffa was not dependent on medium temperature. Moreover, the effect of concentration of $\mathrm{MB}$ in aqueous solution dominated the effect of medium temperature.

Values of $R_{\mathrm{L}}$ were evaluated as $0.059,0.077,0.111$ and 0.111 for $20,30,40$ and $50^{\circ} \mathrm{C}$, respectively. The dimensionless equilibrium parameter $\left(R_{\mathrm{L}}\right)$ indicated that the $\mathrm{MB}$ adsorption on luffa is a relatively irreversible reaction. The $\Delta H^{\circ}$ was found approximately $-20 \mathrm{~kJ} / \mathrm{mol}$. The negative values of $\Delta H^{\circ}$ indicated that MB adsorption onto luffa fiber is an exothermic reaction. The thermodynamic parameters $\left(\Delta G^{\circ}\right.$ and $\left.\Delta S^{\circ}\right)$ for MB adsorption revealed that $\mathrm{MB}$ adsorption occurs spontaneously without requiring high activation energy.

The adsorption isotherms of MB adsorption on L. cylindrica fibers can be well defined by Langmuir model with linear regression correlation coefficient 0.99 . It can be concluded that $L$. cylindrica fiber have homogeneous surface energy. The average MB adsorption capacity of $L$. cylindrica fiber was found as $49 \mathrm{mg} / \mathrm{g}$. The average BET surface area of fibers was calculated as $123 \mathrm{~m}^{2} / \mathrm{g}$. These results are significantly higher than the experienced ones with other cellulose wastes in the literature. 
Kinetic studies on MB adsorption on luffa fiber revealed that the MB adsorption is a pseudo-second order reaction and the intraparticle diffusion model does not fit to experimental data since, the linear regression coefficient of model was lower than 0.99. The MB diffusion coefficients were found as $6.60 \times 10^{-14}$ and $4.13 \times 10^{-13} \mathrm{~m}^{2} / \mathrm{s}$ for medium temperatures of 50 and $30^{\circ} \mathrm{C}$, respectively with lower regression coefficients.

Consequently, L. cylindrica fiber promises being a new adsorbent for removing dye from aqueous solution since it is renewable and sustainable and shows higher adsorption capacity and BET surface area than other cellulose wastes which were investigated by other researchers in the literature. Moreover, $L$. cylindrica fibers can be used as filters, insulation and packing materials because of their tough fibrous vascular system.

\section{References}

[1] F. Alexander, J.P.V. Poots, G. McKay, Adsorption kinetics and diffusional mass transfer processes during color removal from effluent using silica, Ind. Eng. Chem. Process Des. Dev. 17 (1978) 406-410.

[2] M. Dogan, M. Alkan, Y. Onganer, Adsorption of methylene blue from solution onto perlite, Water Air Soil Pollut. 120 (2000) 229-248.

[3] D. Ghosh, G.K. Bhattacharyya, Adsorption of methylene blue on kaolinite, Appl. Clay Sci. 20 (2002) 295-300.

[4] A.H. El-Daly, M.F.A. Habib, B.A.M. El-Din, Kinetics and mechanism of the oxidative color removal from durazol blue $8 \mathrm{G}$ with hydrogen peroxide, Dyes Pigments 57 (2003) 197-210.

[5] G. Annadurai, S.R. Juang, J.D. Lee, Use of cellulose-based wastes for adsorption of dyes from aqueous solutions, J. Hazard. Mater. B92 (2002) 263-274.

[6] G.K. Bhattarcharyya, A. Sarma, Adsorption characteristics of the dye, brilliant green on neem leaf powder, Dyes Pigments 57 (2003) 211-222.
[7] L.M. Hassan, Quaternization and anion exchange capacity of sponge gourd (Luffa cylindrica), J. Appl. Polym. Sci. 101 (2006) 2495-2503.

[8] A.C. Boynard, M.R.J. D'almeida, Water absorption by sponge gourd (Luffa cylindrica)-polyester composite materials, J. Mater. Sci. Lett. 18 (1999) 1789-1791

[9] A. Zampieri, P.T.G. Mabande, T. Selvam, W. Schwieger, A. Rudolph, R. Hermann, H. Sieber, P. Greil, Biotemplating of Luffa cylindrica sponges to self-supporting hierarchical zeolite macrostructures for bio-inspired structured catalytic reactors, Mater. Sci. Eng. C 26 (2006) 130-135.

[10] A.O.V. Tanobe, D.H.T. Sydenstricker, M. Munaro, C.S. Amico, A comprehensive characterization of chemically treated Brazilian sponge-gourd (Luffa cylindrica), Polym. Test. 24 (2005) 474-482.

[11] M.J. Davis, D.C. DeCourly, Luffa sponge gourd: a potential crop for small forms, in: J. Janick, J.E. Simon (Eds.), New Crops, J. Wiley and Sons, New York, 1991, pp. 550-561.

[12] D. Klemm, B. Philipp, T. Heinze, U. Heinze, W. Wagenknecht, Comprehensive Cellulose Chemistry, vol. 1, Wiley VCH, Weinheim, 2001.

[13] O. Inel, N. Kayikci, Bentonit turu killerde boyar madde adsorpsiyonu, T. Eng. Environ. Sci. 14 (1990) 332-334.

[14] Y. Bulut, H. Aydin, A kinetics and thermodynamics study of methylene blue adsorption on wheat shells, Desalination 194 (2006) 259267.

[15] R.H. Perry, D. Green, Perry's Chemical Engineers' Handbook, sixth ed., Mc-Graw Hill Co., Malaysia, 1984.

[16] S. Rattanaphani, M. Chairat, B.J. Bremmer, V. Rattanaphani, An adsorption and thermodynamic study of lac dyeing on cotton pretreated with chitosan, Dyes Pigments 72 (2006) 88-96.

[17] H. Polat, M. Molva, M. Polat, Capacity and mechanism of phenol adsorption on lignite, Int. J. Miner. Process. 79 (2006) 264-273.

[18] B.H. Hameed, A.T.M. Din, A.L. Ahmad, Adsorption of methylene blue onto bamboo-based activated carbon: kinetics and equilibrium studies, J. Hazard. Mater. 141 (2007) 819-825.

[19] J. Crank, The Mathematics of Diffusion, second ed., Clarendon Press, Oxford, 1975. 